\title{
Evaluation of microstructure and mechanical properties of PMMA Matrix composites reinforced with residual YSZ from CAD/CAM Milling process
}

\author{
Mahmut Sertac OZDOGAN1,*, Ramazan KARSLIOGLU2,3 \\ ${ }^{1}$ Department of Prosthodontics, Faculty of Dentistry, Ankara Ylldırım Beyazit University, Ankara, Turkey. \\ ${ }^{2}$ Ankara Yildirim Beyazit University, Faculty of Architecture \& fine Arts, Departmant of Industrial \\ Design, Ankara, Turkey. \\ ${ }^{3}$ Ankara Ylldırım Beyazit University, AYBU Central Research Laboratory Research and Application Center, \\ Ankara, Turkey.
}

\section{N F O R M A T I O N}

\section{Article History}

Received $8^{\text {th }}$ March 2021

Received revised

$11^{\text {th }}$ April 2021

Accepted 15th April 2021

Available online

15 $5^{\text {th }}$ May 2021

\section{K E Y W O R D S}

Recycling

zirconium oxide

Polymethyl methacrylate

Microhardness

Surface roughness

Density
Background: Reinforcement of dental acrylics with fillers has yielded positive results. Different proportions of fillers have been added to strengthen the dental acrylics, but no consensus has been reached.

Aim: The purpose of this study was to investigate the effects of the addition of different concentrations of yttria-stabilized zirconium (YSZ) obtained from the residues generated from the CAD-CAM milling of YSZ on the microstructure and mechanical properties of poly-methyl-methacrylate (PMMA)-YSZ composites.

Materials and methods: Composite materials with different amounts 0.0 to $70.0 \%$ by weight) of recycled YSZ reinforced PMMA resin matrix were produced. Scanning electron microscope (SEM), energy dispersive electron spectrometer (EDS) and Fourier Transform Infrared Spectrometer (FTIR) were used for microstructural analysis. Among the mechanical properties, the Vickers microhardness test method for hardness, 2D profilometer for surface roughness and composite densities were evaluated by Archimedes method. Data were analyzed using a one-way analysis of variance (ANOVA) at a pre-set alpha of 0.05 .

Results: Microhardness and density increased until $60 \%$ by weight $Y S Z$ addition, while surface roughness remained unchanged but increased after $60 \%$ by weight YSZ addition. The addition of more than $60 \%$ by weight of YSZ caused agglomeration in the microstructures. The mechanical properties of poly-methylmethacrylate decreased with more than $60 \%$ YSZ by weight.

Conclusion: Reinforcement of PMMA with residue zirconia powder will increase the usage chance of residue YSZ powder and provide a safer use of PMMA.

\section{Introduction}

Polymethylmethacrylate (PMMA) is one of the most preferred prosthodontic material in dentistry owing to the reasons such as low-cost, simple application and easy polishing [1,2]. PMMA based provisional restoration is an important step that should not be neglected in the fixed prosthetic treatment process in order to protect the prepared tooth from heat and food to provide aesthetics, function, formation of the gum form and occlusion for a certain period [3,4].

Temporary restorations undergo repeated chewing forces and require specific mechanical properties to withstandlong-span fixed prostheses, temporomandibular

Correspondence: ${ }^{*}$ Corresponding author Email Address: msozdogan@ybu.edu.tr

How to cite this article: OZDOGAN MS, KARSLIOGLU R. Evaluation of microstructure and mechanical properties of PMMA Matrix composites reinforced with residual YSZ from CAD/CAM Milling process. Int J Dent Mater 2021;3(2): 37-44. DOI: http://dx.doi.org/10.37983/IJDM.2021.3201 
joint disorders, and parafunctional habits [5]. However, PMMA has insufficient mechanical strength and surface hardness [2], prolonged use can cause cracking or fracture of temporary restorations, especially in long-span fixed prostheses and areas with heavy occlusal load in the posterior region. When temporary restorations are broken, they can damage oral tissues and even be swallowed by the patient. The surface hardness of PMMA is low; hence the material is relatively softer and possibly become rough during the chewing process in the oral cavity. Consequent to this, the surface of PMMA are colonized easily by microorganisms [6-8].

In recent years, many different material additions such as metal wires [9], fibre [10-13], nanodiamond [14], metal oxide nanofillers such as silver $[15,16]$, titanium [17-19], aluminum and zirconium oxide [20, 21] to resin matrix have been studied to improve the mechanical properties of PMMA. Some of these additions have the same disadvantages, such as low corrosion resistance [9], tissue irritation, etc. [7]. The hardness, density and roughness of the provisional restorative materials change according to the polymer and the reinforcement type [22]. Zirconia with superior biocompatibility, mechanical strength, high density, high surface hardness [23], good chemical resistance, good thermal stability [24] is a superior reinforcement material for PMMA.

Nowadays, the recycling and reuse of ceramic materials are even more important because of the environmental issue and the high cost of mining and transporting pure raw material [25]. The machining of crowns by CAD/CAM (Computer-assisted design/computerassisted machining) can produce a waste of approximately $30 \%$ of the initial blank, generating a significant economic loss for the prosthetic laboratories. Zirconia residues have a high economic value and potential for recycling [26].

Therefore, this study aimed to evaluate the effect of incorporating residue YSZ on hardness, density, and roughness on PMMA. There are a few studies in the literature about YSZ reinforcement PMMA. However, they were mainly focused on low amount YSZ addition (10 wt\%) to PMMA $[27,28]$. However, there are no studies about the high percentage of YSZ reinforced to PMMA matrix in literature.
In the present study, a commercially available cold cured provisional poly-methyl methacrylate (PMMA) powder and methyl methacrylate (MMA) (Integra, Ankara, Turkey) as base liquid were selected as matrix materials. Residue Yttria-stabilized zirconia-milled powder (Zirking, Huge Dental, China) were used as a reinforcing material to prepare the composite specimens.

\subsection{Samples preparation}

The residue yttria-stabilized $\mathrm{ZrO} 2$ powders and provisional PMMA powder were pre-weighted using an electronic balance (Radwag AS 60/220.R2 Dual Range Analytical Balance, Radwag USA L.L.C., FL, USA) to ensure $0.0 \mathrm{wt} \%, 12.5 \mathrm{wt} \%, 25 \mathrm{wt} \%, 30 \mathrm{wt} \%, 35$ wt $\%, 40 \mathrm{wt} \%, 50 \mathrm{wt} \%, 60 \mathrm{wt} \%, 65 \mathrm{wt} \%$, and $70 \mathrm{wt} \%$ concentrations (Table 1 ).

Zirconia blocks residue powders were added to the acrylic resin powder and mixed manually with a stainless-steel spatula until homogeneously dispersed. Subsequently, MMA liquid was added and thoroughly mixed. The dough was poured into a stainless steel mould of $10 \times 2 \mathrm{~mm}$ cylindrical holes, and samples were allowed to cure in a pressure vessel (Vertex Poly Cure25, Vertex-Dental, Zeist, Netherlands) under 2.5 atmospheric pressure at $55^{\circ} \mathrm{C}$ for 10 minutes. After polymerization, the specimens were wet-polished with 800-grit, 1000-grit and 1200-grit silicon carbide papers, respectively $(n=10)$.

The microstructure of the fractured surfaces of prepared samples was studied using a scanning electron microscope (SEM JSM-6060 LV, JEOL, Tokyo, Japan). Chemical composition was analyzed using an Electron Dispersive Spectrometer (EDS) (Hitachi SU 5000, Japan). Fourier transform infrared spectroscopy (version 660-IR FT-R Spectrometer, Agilent Technologies, Santa Clara, USA) was used to detect the functional groups. Vickers hardness of the samples was measured using a microhardness device (HMV, Shimadzu, Kyoto, Japan). Specimens of $10 \mathrm{~mm}$ diameter and $2 \mathrm{~mm}$ thickness were subjected to a load of $50 \mathrm{~N}$ for 10 seconds for hardness measurement. Densities of unreinforced PMMA and yttria-stabilized $\mathrm{ZrO}_{2}$ reinforced PMMA matrix samples were measured using the Archimedes density measurement method. The surface roughness (Ra) test was performed with a profilometer (Surface Roughness Tester SJ-201, Mitutoyo, Kawasaki, Japan) to measure the arithmetic mean roughness of the surfaces. The cut off was set at $0.8 \mathrm{~mm}$, and the total transverse length was $1.25 \mathrm{~mm}$. 
Table 1. Powder PMMA and liquid MMA weights with residue zirconia weight percentages of groups.

\begin{tabular}{ccccc}
\hline Groups & Zirconia (wt\%) & Zirconia (g) & PMMA Powder $\mathbf{( g )}$ & Monomer $(\mathbf{m L})$ \\
\hline 1 & 0.00 & 0.00 & 23.50 & 10.00 \\
2 & 12.50 & 2.94 & 20.56 & 10.00 \\
3 & 25.00 & 5.88 & 17.62 & 10.00 \\
4 & 30.00 & 7.00 & 16.45 & 10.00 \\
5 & 35.00 & 8.23 & 15.27 & 10.00 \\
6 & 40.00 & 9.40 & 14.10 & 10.00 \\
7 & 50.00 & 11.75 & 11.75 & 10.00 \\
8 & 60.00 & 14.10 & 9.40 & 10.00 \\
9 & 65.00 & 15.27 & 8.23 & 10.00 \\
10 & 70.00 & 16.40 & 7.05 & 10.00 \\
\hline
\end{tabular}
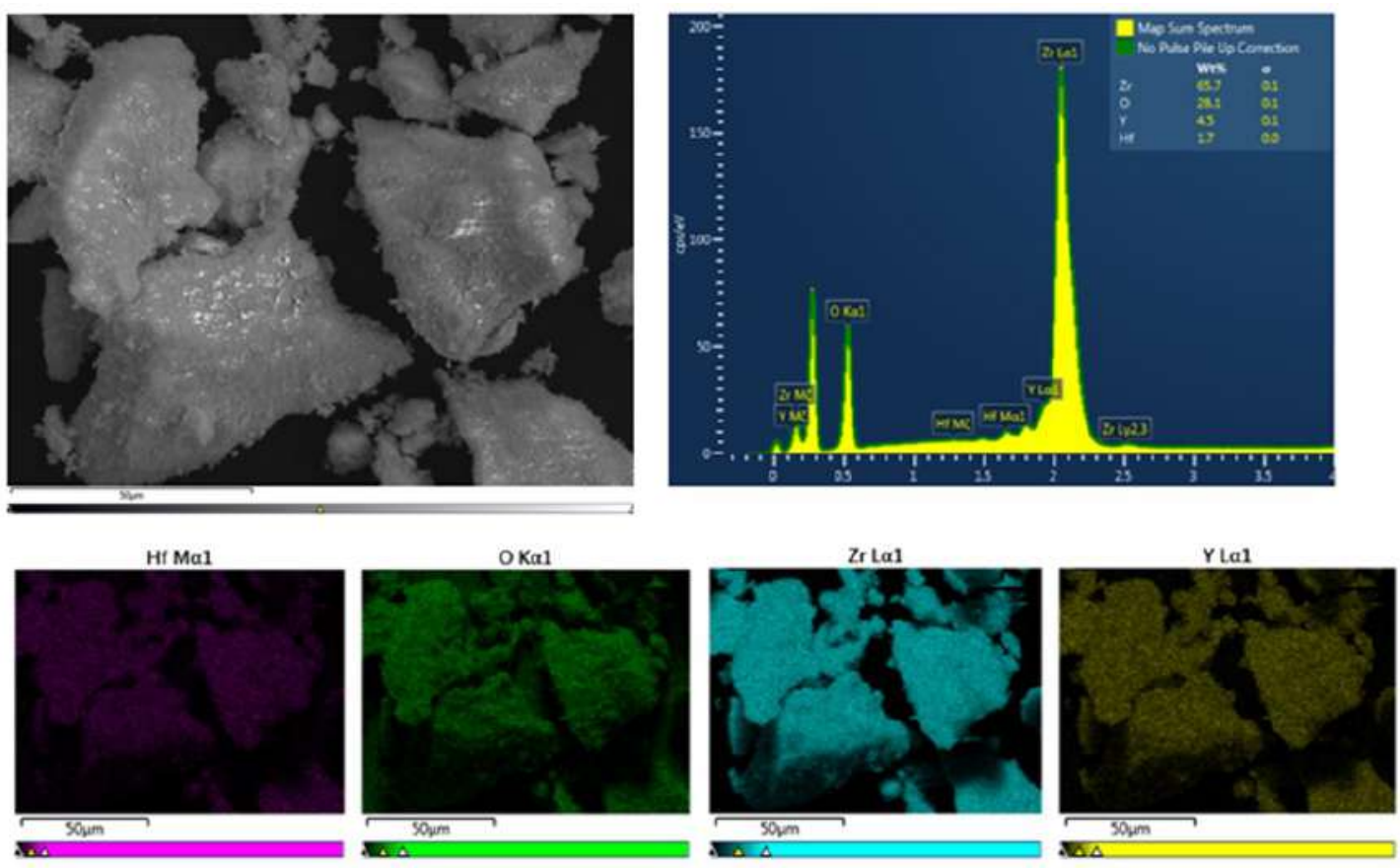

Figure 1. YSZ particles SEM image and EDS analysis.
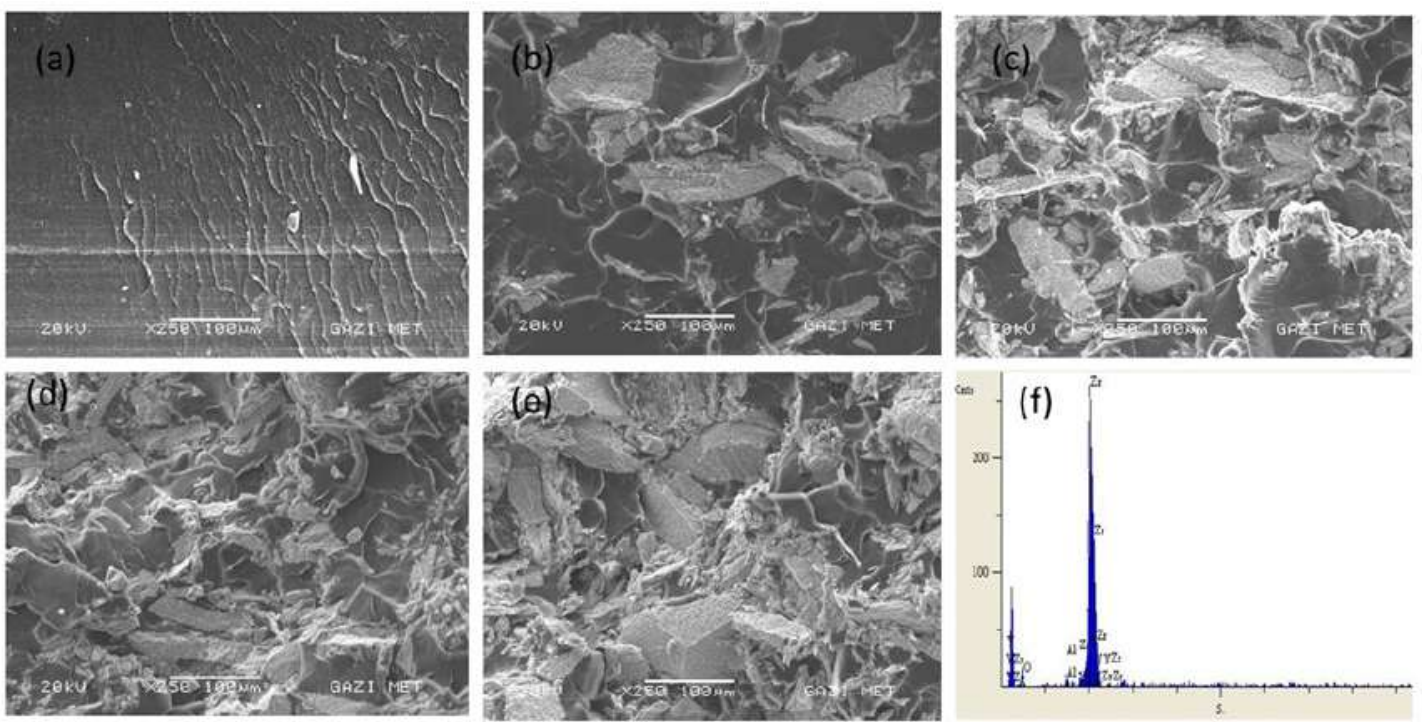

Figure 2. SEM of Recycled stabilized zirconia reinforced PMMA acrylic (a) 0.0 wt\%, (b) 25 wt\%, (c) 50 wt\%, (d) 60 wt\%, (e) 65 wt\% and (f) EDS analysis 


\subsection{Statistical analysis}

Data quality control and statistical analyses were done using IMB SPSS Statistics Version 25.0 (IBM SPSS, Chicago, IL, USA). Normal distribution and homogeneity of variance showed with Shapiro-Wilk and Levene's tests. Data were analyzed using a one-way analysis of variance (ANOVA) with the Tukey post-hoc test at a pre-set alpha of 0.05 .

\section{Results}

\subsection{SEM analysis and microstructural characteristics}

According to SEM analysis (Figure 1), residue YSZ particles size was between $500 \mathrm{~nm}$ and $70 \mu \mathrm{m}$. According to EDS results, YSZ particles chemical compositions consist of $65.7 \mathrm{Zr} w \mathrm{t} \%, 28.10 \mathrm{wt} \%, 4.5 \mathrm{Y}$ wt $\%$ and $1.7 \mathrm{Hf}$ wt\%. It can be seen from Figure 1 that EDS map analysis indicates homogeneous distributions of all phases in the particles. Figure 2 shows SEM microstructure and EDS analysis of unreinforced PMMA and $\mathrm{ZrO}_{2}$ reinforced composites fracture structures.

Unreinforced PMMA fractured surfaces were very dense, smooth and homogeneous without porosity (Figure 2a). With the addition of YSZ to PMMA, the surface roughness of fractured surfaces significantly increased. Additionally, fracture surfaces roughness proportionally increased with increasing YSZ amount in structure Figures 2b-e. According to Figure 2e, over 60 wt\% YSZ amounts caused YSZ agglomeration in the matrix. There are some voids among the YSZ agglomerated particles because of the unwet YSZ by PMMA matrix. These vacancies reduce the mechanical properties. FTIR test was carried out on unreinforced PMMA, and YSZ reinforced PMMA to evaluate the different active groups.

Figure 3 shows FTIR analysis results of unreinforced PMMA, 25.0 wt \%, 40.0 wt\%, 60.0 wt\%, 70.0 wt\% YSZ reinforced PMMA. Five new strong absorption picks were seen at wavenumbers of 2919.3, 1616.1, 1535.6, 598.4 and $567.7 \mathrm{~cm}^{-1}$ in the FTIR spectrum of YSZ reinforced PMMA composites compared to unreinforced PMMA. $1616.1 \mathrm{~cm}^{-1}$ resulted from the tension vibration of the hydroxyl groups for the YSZ surface. The stress vibration of the $\mathrm{C}-\mathrm{H}$ bond at 2940 and 3000 $\mathrm{cm}^{-1}$ and that YSZ bond in the range of $1530-1620 \mathrm{~cm}^{-1}$ showed that PMMA successfully bond to YSZ (Figure 3). However, $70 \mathrm{wt} \%$ YSZ FTIR peaks are not strong as other FTIR peaks because of YSZ agglomerations and insufficient wetting by PMMA. Therefore, only weak chemical bonding between the PMMA and YSZ occurs over the 60 wt.\% YSZ addition. These results were exactly matching with SEM images.

Figure 4 represents Vickers hardness and density variation with YSZ amount. Microhardness increased with increasing YSZ amount until $60 \mathrm{wt} \%$ YSZ addition from 23.45 to 31.18 (Table 2), indicating that surface hardness increased by over 24\%. However, above 60 wt $\%$ YSZ addition, microhardness decreased because of $\mathrm{ZrO}_{2}$ agglomeration in the composite structure. This issue proved successfully load transfer mechanisms that occur in the composite structures. Densities increased with the increasing second phase (YSZ) amount in the composite due to the higher densities of YSZ, which is 5.97 compared to the density of PMMA which is 1.17. This shows that YSZ density is 5.1 times higher than PMMA; hence density increased with the increasing YSZ amount.

As shown in Figure 5, unreinforced PMMA and YSZ reinforced PMMA matrix composites, low amount YSZ addition does not significantly affect the surface roughness of composites. However, with the increasing YSZ addition, surface roughness increased proportionally. Over $60 \mathrm{wt} \%$ surface roughness sharply increased due to the high amount of YSZ agglomerations.

The mean values of Vickers hardness in Table 2 showed statistically significant differences $(\mathrm{p}<0.05)$. There was no statistically significant difference between groups up to $25 \%$ YSZ addition $(p<0.05)$. A maximum increase in microhardness was observed at 60 wt\% zirconia $(\mathrm{p}<0.05)$ (Table 2). A sudden decrease was observed in the group containing 65 wt\% zirconia, whereas 70 wt $\%$ zirconia powder addition was found to have the least microhardness $(\mathrm{p}<0.05)$.

The mean values of surface roughness in Table 2 showed statistically significant differences $(\mathrm{p}<0.05)$. The addition of $50 \mathrm{wt} \%$ zirconia did not make a significant difference in the roughness, while $60 \mathrm{wt} \%, 65$ $w \mathrm{t} \%$ and $70 \mathrm{wt} \%$ YSZ powder produced a significant increase in the roughness $(\mathrm{p}<0.05)$.

\section{D iscussion}

This study showed that the residual powders obtained 


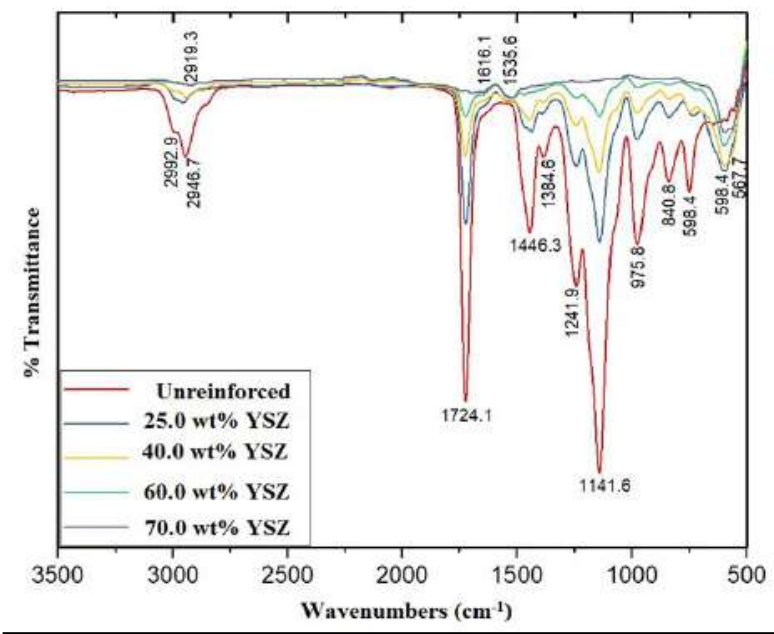

Wavenumbers $\left(\mathrm{cm}^{-1}\right)$

Figure 3. FTIR analysis of unreinforced, and reinforced PMMA with 25.0 wt \%, 40.0 wt\%, 60.0 $w t \%, 70.0$ wt $\%$ of YSZ

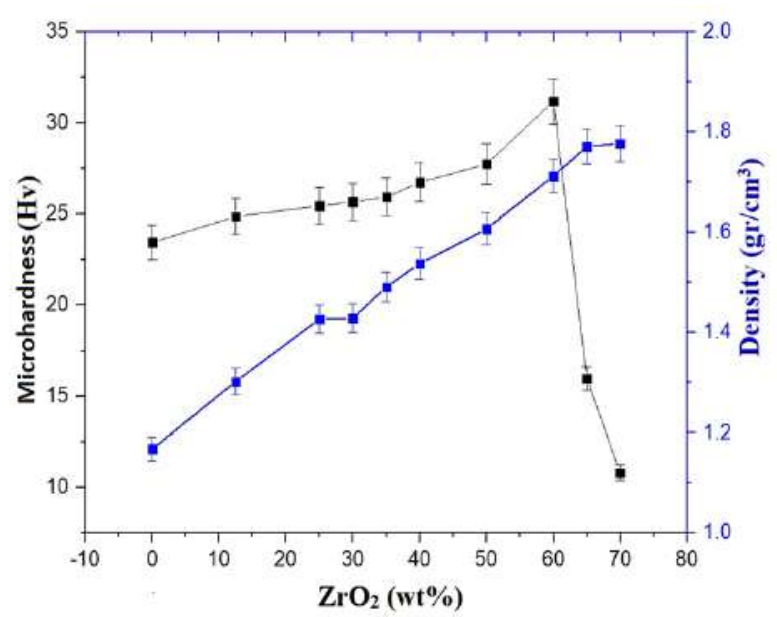

Figure 4. Microhardness and density of PMMA with various concentrations of $\mathrm{ZrO}_{2}$ amount.

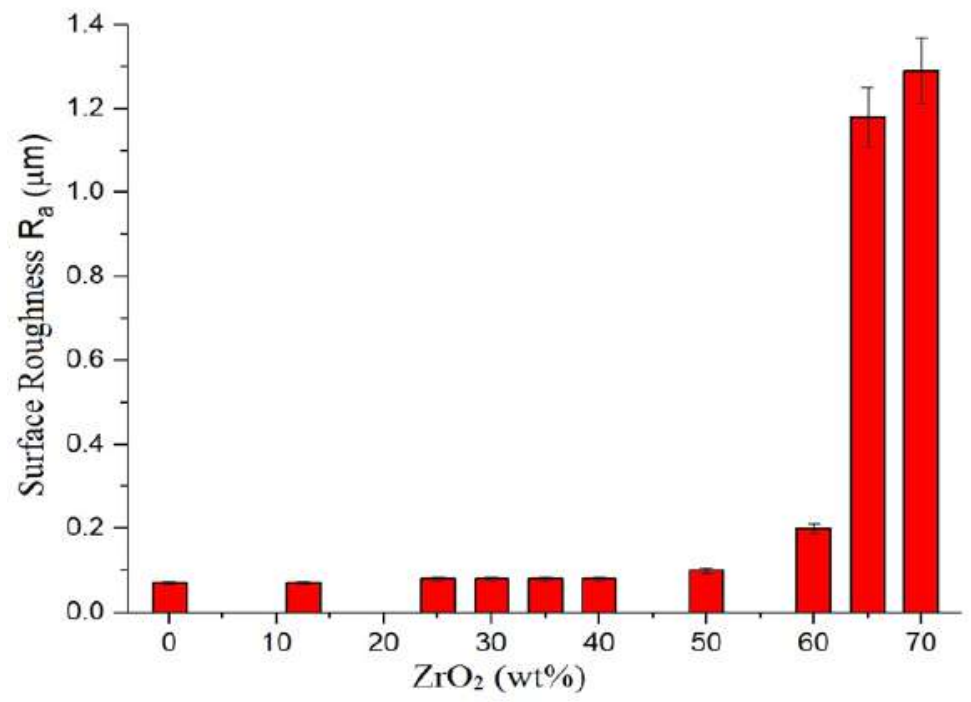

\section{Figure 5. Surface roughness (Ra) variation with $\mathrm{ZrO}_{2}$ concentration}

Table 2. Mean and Standard deviation (SD) of Vickers hardness $\left(\mathrm{kg} / \mathrm{mm}^{2}\right)$, surface roughness and density of reinforced and unreinforced PMMA resin.

\begin{tabular}{ccccc}
\hline & Weight (\%) & Vickers Hardness & $\begin{array}{c}\text { Surface } \\
\text { Roughness }\end{array}$ & Density \\
\hline 1 & 0.00 & $23.45 \pm 1.08^{\mathrm{A}}$ & $0.07 \pm 0.01^{\mathrm{A}}$ & $1.17 \pm 0.03^{\mathrm{A}}$ \\
2 & 12.50 & $24.87 \pm 1.01 \mathrm{AC}$ & $0.07 \pm 0.01^{\mathrm{A}}$ & $1.30 \pm 0.07^{\mathrm{B}}$ \\
3 & 25.00 & $25.44 \pm 3.59 \mathrm{AC}$ & $0.08 \pm 0.03^{\mathrm{A}}$ & $1.43 \pm 0.02^{\mathrm{C}}$ \\
4 & 30.00 & $25.66 \pm 2.34 \mathrm{AC}$ & $0.08 \pm 0.02^{\mathrm{A}}$ & $1.43 \pm 0.05^{\mathrm{C}}$ \\
5 & 35.00 & $25.03 \pm 3.12^{\mathrm{AC}}$ & $0.08 \pm 0.01^{\mathrm{A}}$ & $1.49 \pm 0.04^{\mathrm{CD}}$ \\
6 & 40.00 & $26.73 \pm 1.03^{\mathrm{BC}}$ & $0.08 \pm 0.00^{\mathrm{A}}$ & $1.54 \pm 0.10^{\mathrm{DE}}$ \\
7 & 50.00 & $27.73 \pm 2.49^{\mathrm{BC}}$ & $0.10 \pm 0.03^{\mathrm{A}}$ & $1.61 \pm 0.02^{\mathrm{E}}$ \\
8 & 60.00 & $31.18 \pm 1.08^{\mathrm{D}}$ & $0.18 \pm 0.06^{\mathrm{B}}$ & $1.71 \pm 0.01^{\mathrm{F}}$ \\
9 & 65.00 & $15.98 \pm 0.80^{\mathrm{E}}$ & $0.20 \pm 0.00^{\mathrm{C}}$ & $1.77 \pm 0.06^{\mathrm{F}}$ \\
10 & 70.00 & $10.81 \pm 0.45^{\mathrm{F}}$ & $0.29 \pm 0.00^{\mathrm{D}}$ & $1.78 \pm 0.10^{\mathrm{F}}$ \\
\hline
\end{tabular}

Within a column, values identified using similar upper-case letters are not significantly different. 
after CAD/CAM machining had improved the mechanical properties of PMMA.

In the present study, Unreinforced and various amount residues YSZ reinforced PMMA matrix composites were successfully produced. The addition of residue zirconia powders addition at higher amounts increased Vickers hardness and density but did not affect the surface roughness of the PMMA composites.

PMMA fully covered all YSZ particles until $60 \mathrm{wt} \% \mathrm{YSZ}$ addition, and good bonding between the PMMA and YSZ was observed with the formation of a very dense microstructure. Similarly, composites microhardness and densities increased with increasing YSZ amount in the composite structure.

Surface roughness was not significantly changed until $60 \mathrm{wt} \%$ YSZ additions. However, over the $60 \mathrm{wt} \% \mathrm{YSZ}$ addition sharply increased surface roughness.

However, the microhardness and roughness values of PMMA acrylic resin groups with less than 50 wt\% zirconia powder addition did not differ significantly from the control group ( $\mathrm{p}>0.05)$.

Temporary crown material may wear out due to functional forces and foods; thus, it must have adequate abrasion resistance. Adding inorganic filler into PMMA can increase microhardness, especially the addition of hard fillers such as $\mathrm{ZrO}_{2}$ [27]. By examining the acrylic resin hardness, residual monomer amount [24], resistance to abrasion [29], and ease of finishing of the material [9] are determined.

The results of the present study were in agreement with a study presented by Ahmed et al. (2014) that evaluated the hardness of $\mathrm{PMMA} / \mathrm{ZrO}_{2}$ nanocomposites with different $\mathrm{ZrO}_{2}$ concentrations (1\%, 3\%, 5\%, $7 \%$ ) using the Vickers hardness test [27]. They found that all specimens showed hardness mean values higher than that control group, and PMMA specimen with $7 \%$ zirconium oxide nanofillers showed the highest mean hardness significantly.

Over 60 wt\% YSZ additions to PMMA caused YSZ agglomeration in the structure and decreased mechanical properties because of vacancies among the agglomerated YSZ. This agglomeration can be attributed to insufficient wetting by PMMA.
With the addition of residual zirconia powder, Vickers hardness was increased up to $60 \mathrm{wt} \%$ of YSZ, while it decreased significantly after adding $65 \mathrm{wt} \%$ and $70 w t \%$ powder. The decrease in surface hardness with higher filler loading was caused by poor adhesion of the particles to the resin matrix and filler clustering within the matrix [28]. Zhang et al. investigated the effect of zirconia nanoparticles and aluminum borate whiskers (ABW) in PMMA denture bases on the surface hardness at concentrations of $1 \mathrm{wt} \%, 2 \mathrm{wt} \%, 3$ wt $\%$ and 4 wt $\%$ [28]. The results showed an increase in surface hardness with an increase in $\mathrm{ZrO}_{2} / \mathrm{ABW}$ content, and the optimum hardness was achieved at 3 wt $\% \mathrm{ZrO}_{2}$ nanoparticles.

In another study, Ergun et al. (2018) [30] investigated the physical and mechanical properties of PMMA reinforced with various ratios of zirconium oxide nanoparticles and observed a significant increase in hardness and surface roughness.

Hardness is the resistance of a material to plastic deformation. Surface hardness can be used as an indicator of density, and it can be hypothesized that a denser material would be more resistant to wear and surface deterioration [31].

Vojdani et al. (2012) [7] reinforced PMMA mixtures with $\mathrm{Al}_{2} \mathrm{O}_{3}$ at loadings of $0.5,1,2.5$ and $5 \mathrm{wt} \%$. They stated that Vickers hardness values increased linearly but could not find any difference in surface roughness. The Vickers hardness significantly increased after the incorporation of 2.5 and $5 \mathrm{wt} \% \mathrm{Al}_{2} \mathrm{O}_{3}$ addition. No significant difference was detected in surface roughness between the reinforced and control groups.

The addition of recycled zirconium powder has been shown to increase microhardness, as in previous studies. This microhardness increase is due to the hard zirconium oxide $\left(\mathrm{ZrO}_{2}\right)$. An increase in microhardness was observed due to the crushing tip of the microhardness device hitting zirconium metal oxides.

One of the problems that surface roughness can cause in temporary dentures is colour change, adhesion of food and plaque formation, depending on the amount of roughness [32].

In the present study, with the addition of $60 \%$ or more recycled zirconia powder by weight, the roughness increase was found to be below 0.2 micrometres, which 
can be accepted as clinically [33]. The roughness was directly proportional to the amount of recycled zirconia powder incorporated into the resin matrix. This increase is because of the zirconium particles in the matrix approaching the surface.

In the study groups, a statistically significant difference in density changes up to $50 \%$ zirconia, but no difference was found with the addition of $60 \%$ or more zirconia. As the recycled zirconia powder content increased, their values increased due to decreased pores [34]. The effect of nanoparticles on the mechanical properties of PMMA depends on several factors, including polymer particle interface, particle size, fabrication method, and particle dispersion in the PMMA matrix [35].

\section{Conclusion}

Different amount of residual YSZ reinforced PMMA was produced within a pressure vessel system. FTIR results showed good bonding between the residue YSZ and the PMMA matrix. According to SEM results, residue YSZ was homogenously distributed in the PMMA matrix until 60 wt.\%. Over 60 wt.\% additions caused YZS agglomerations in the matrix. Also, a high amount of residue YSZ addition (60 wt.\%) decreased mechanical properties because of unwetted residue YSZ and space between the agglomerated YSZ powders. Another effect of high amount second phase additions sharply increased surface roughness. Composite structure density was increased with increasing residue YSZ additions due to the higher density of residue YSZ.

Provisional PMMA with superior mechanical properties was created using recycled zirconia without the need for special additional processing steps. Best mechanical and structural properties were achieved with 60 wt.\% residue YSZ additions.

Conflicts of interest: Authors declared no conflicts of interest.

\section{Financial support: None}

\section{References}

1. Maji P, Choudhary RB, Majhi M. Structural, optical and dielectric properties of $\mathrm{ZrO}_{2}$ reinforced polymeric nanocomposite films of polymethylmethacrylate (PMMA). Optik, 2016;127:4848-53. https://doi.org/10.1016/j.ijleo.2016.02.025
2. Ahmed Omran A, Zainal Arifin A. Effect of Al2O3/ $\mathrm{ZrO} 2$ reinforcement on the mechanical properties of PMMA denture base. J Reinf Plastic Comp. 2011;30:86-93. https://doi.org/10.1177/0731684410379511

3. Gratton DG, Aquilino SA. Interim restorations. Dent Clin North Am. 2004;48:vii-497.

https://doi.org/10.1016/j.cden.2003.12.007

4. Psarri C, Kourtis S. Effect of fiber-reinforcement on the strength of polymer materials for provisional restorations: An in vitro study. J Esthet Restor Dent. 2020;32:433-40. https://doi.org/10.1111/jerd.12586

5. Kadiyala KK, Badisa MK, Anne G, et al. Evaluation of Flexural Strength of Thermocycled Interim Resin Materials Used in Prosthetic Rehabilitation- An Invitro Study. J Clin Diagn Res. 2016;10:ZC91-ZC95. https://doi.org/10.7860/JCDR/2016/20020.8566

6. Azevedo A, Machado AL, Vergani CE, et al. Magnani R. Effect of disinfectants on the hardness and roughness of reline acrylic resins. J Prosthodont. 2006;15:235-42. https://doi.org/10.1111/j.1532849X.2006.00112.x

7. Vojdani M, Bagheri R, Khaledi AAR. Effects of aluminum oxide addition on the flexural strength, surface hardness, and roughness of heat-polymerized acrylic resin. J Dent Sci. 2012;7:238-44. https:// doi.org/10.1016/j.jds.2012.05.008

8. Neppelenbroek KH, Pavarina AC, Vergani CE, Giampaolo ET. Hardness of heat-polymerized acrylic resins after disinfection and long-term water immersion. J Prosthet Dent. 2005;93:171-6. https:// doi.org/10.1016/j.prosdent.2004.10.020

9. Vallittu PK, Lassila VP. Effect of metal strengthener's surface roughness on fracture resistance of acrylic denture base material. J Oral Rehabil. 1992;19:38591. https://doi.org/10.1111/j.13652842.1992.tb01580.x

10. Vallittu PK. Flexural properties of acrylic resin polymers reinforced with unidirectional and woven glass fibers. J Prosthet Dent. 1999;81:318-26. https:// doi.org/10.1016/S0022-3913(99)70276-3

11. Kanie T, Fujii K, Arikawa H, Inoue K. Flexural properties and impact strength of denture base polymer reinforced with woven glass fibers. Dent Mater. 2000;16:150-8. https://doi.org/10.1016/S0109-5641 (99)00097-4

12. Gad M, ArRejaie AS, Abdel-Halim MS, Rahoma A. The Reinforcement Effect of Nano-Zirconia on the Transverse Strength of Repaired Acrylic Denture Base. Int J Dent. 2016;2016:7094056. https:// doi.org/10.1155/2016/7094056

13. Ruyter IE, Ekstrand K, Bjork N. Development of carbon/graphite fiber reinforced poly (methyl methacrylate) suitable for implant-fixed dental bridges. Dent Mater. 1986;2:6-9. https://doi.org/10.1016/S0109$\underline{5641(86) 80062-8}$

14. Mangal U, Kim JY, Seo JY, et al. Novel Poly(methyl 
Methacrylate) Containing Nanodiamond to Improve the Mechanical Properties and Fungal Resistance. Materials (Basel). 2019;12:3438. https:// doi.org/10.3390/ma12203438

15. Ghaffari T, Hamedirad F, Ezzati B. In Vitro Comparison of Compressive and Tensile Strengths ofAcrylic Resins Reinforced by Silver Nanoparticles at $2 \%$ and 0.2\% Concentrations. J Dent Res Dent Clin Dent Prospects. 2014;8:204-9.

16. Singho ND, Lah NAC, Johan MR, Ahmad R. FTIR studies on silver-poly (methylmethacrylate) nanocomposites via in-situ polymerization technique. Int $\mathrm{J}$ Electrochem Sci. 2012;7: 5596-603.

17. Totu EE, Cristache CM, Voicila E, Oprea O, et al. On physical and chemical characteristics of Poly (methylmethacrylate) nanocomposites for dental applications. I. Mater. Plast. 2017;54:666. https:// doi.org/10.37358/MP.17.4.4922

18. Hamouda IM, Beyari MM. Addition of glass fibers and titanium dioxide nanoparticles to the acrylic resin denture base material: comparative study with the conventional and high impact types. Oral Health Dent Manag. 2014;13:107-12.

19. Sodagar A, Bahador A, Khalil S, et al. The effect of $\mathrm{TiO}_{2}$ and $\mathrm{SiO}_{2}$ nanoparticles on flexural strength of poly (methyl methacrylate) acrylic resins. J Prosthodont Res. 2013;57:15-19. https://doi.org/10.1016/ j.jpor.2012.05.001

20. Gad MM, Abualsaud R, Rahoma A, et al. Effect of zirconium oxide nanoparticles addition on the optical and tensile properties of polymethyl methacrylate denture base material. Int $J$ Nanomedicine. 2018;13:283. https://doi.org/10.2147/IJN.S152571

21. Alhavaz A, Rezaei Dastjerdi M, Ghasemi A, et al. Effect of untreated zirconium oxide nanofiller on the flexural strength and surface hardness of autopolymerized interim fixed restoration resins. J Esthet Restor Dent. 2017;29:264-9. https://doi.org/10.1111/ jerd. 12300

22. Basant G, Reddy YG. The effect of incorporation, orientation and silane treatment of glass fibers on the fracture resistance of interim fixed partial dentures. J Indian Prosthodont Soc. 2011;11:45-51. https:// doi.org/10.1007/s13191-011-0059-8

23. Mallineni SK, Nuvvula S, Matinlinna JP, et al. Biocompatibility of various dental materials in contemporary dentistry: a narrative insight. J Investig Clin Dent. 2013;4(1):9-19. https://doi.org/10.1111/j.20411626.2012.00140.x

24. Fangqiang FAN, Zhengbin XIA, Qingying LI, et al. ZrO2/PMMA nanocomposites: preparation and its dispersion in polymer matrix. Chin J Chem Eng. 2013;21:113-20. https://doi.org/10.1016/S1004-9541 (13)60448-6

25. Siligardi C, Barbi S, Casini R, Tagliaferri L, Remigio V. Recycling of yttria-stabilized zirconia waste powders in glazes suitable for ceramic tiles. Int J Appl
Ceram Technol. 2017;14:1236-47.

https://doi.org/10.1111/ijac.12702

26. Gouveia PF, Schabbach LM, Souza JCM, Henriques B, Labrincha JA, Silva FS, Mesquita-Guimarães J. New perspectives for recycling dental zirconia waste resulting from $\mathrm{CAD} / \mathrm{CAM}$ manufacturing process. J Clean Prod. 2017;152:454-63.

https://doi.org/10.1016/j.jclepro.2017.03.117

27. Ahmed MA, Ebrahim MI. Effect of zirconium oxide nano-fillers addition on the flexural strength, fracture toughness, and hardness of heat-polymerized acrylic resin. World J Nano Sci Eng. 2014;4:50-57. https:// doi.org/10.4236/wjnse.2014.42008

28. Zhang XY, Zhang XJ, Huang ZL, et al. Hybrid effects of zirconia nanoparticles with aluminum borate whiskers on mechanical properties of denture base resin PMMA. Dent Mater J. 2014;33:141-6. https:// doi.org/10.4012/dmj.2013-054

29. Lee SY, Lai YL, Hsu TS. Influence of polymerization conditions on monomer elution and microhardness of autopolymerized polymethyl methacrylate resin. Eur J Oral Sci. 2002;110:179-83. https://doi.org/10.1034/ j.1600-0722.2002.11232.x

30. Ergun G, Sahin Z, Ataol AS. The effects of adding various ratios of zirconium oxide nanoparticles to poly(methyl methacrylate) on physical and mechanical properties. J Oral Sci. 2018;60:304-15. https:// doi.org/10.2334/josnusd.17-0206

31. Milia E, Cumbo E, Cardoso RJ, Gallina G. Current dental adhesives systems. A narrative review. Curr Pharm Des. 2012;18:5542-52. https:// doi.org/10.2174/138161212803307491

32. Mickeviciute E, Ivanauskiene E, Noreikiene V. In vitro color and roughness stability of different temporary restorative materials. Stomatologija. 2016;18:6672.

33. International Organization for Standardization (2008) Dentistry- Base polymers-Denture base polymers. ISO 20795-1:2008, Geneve.

34. Gain AK, Song HY, Lee BT. Microstructure and mechanical properties of porous yttria stabilized zirconia ceramic using poly methyl methacrylate powder. Scripta Materialia. 2006;54:2081-5. https:// doi.org/10.1016/j.scriptamat.2006.03.009

35. Puigdollers AR, Illas F, Pacchioni G. Structure and properties of zirconia nanoparticles from density functional theory calculations $\mathrm{J}$ Phys Chem. C 2016;120: 4392-402. $\quad$ https://doi.org/10.1021/ acs.jpcc. 5 b 12185 